\title{
Respiratory disease in systemic lupus erythematosus: correlation with results of laboratory tests and histological appearance of muscle biopsy specimens
}

\author{
S A Evans, N D Hopkinson, W J M Kinnear, L Watson, R J Powell, I D A Johnston
}

\begin{abstract}
Background In systemic lupus erythematosus, certain laboratory tests and evidence from muscle biopsy specimens of lymphocytic vasculitis reflect disease activity. A study was designed to determine if such indices predict respiratory lesions, and in particular whether the presence of vasculitis in quadriceps muscle reflects respiratory muscle function.

Methods Twenty seven 27 patients with systemic lupus erythematosus were studied, ten of whom were consecutive untreated patients and 17 having clinically active disease and being treated. They were prospectively evaluated on the basis of erythrocyte sedimentation rate, lymphocyte count, $\mathrm{C} 3$ degradation products, quadriceps muscle biopsy, spirometry, lung volumes, carbon monoxide transfer factor, and mouth pressure during a maximal sniff.

Results Lung function test results were abnormal in 12 patients. Vital capacity was reduced in seven, carbon monoxide transfer factor capacity in five, and mouth pressure was low $(<70 \%$ predicted) in ten. Lymphocytic vasculitis was seen in the muscle biopsy specimens of ten patients. No correlation was found between laboratory tests and lung function or mouth pressure, or between the presence of lymphocytic vasculitis and mouth pressure. In untreated patients, those with lymphocytic vasculitis had lower spirometric values.

Conclusions In systemic lupus erythematosus, evidence from muscle biopsy specimens of lymphocytic vasculitis is not predictive of impaired inspiratory muscle function as measured by mouth pressure. In untreated patients there were relationships between some laboratory test results and respiratory function, but this was not the case for the whole group. In systemic lupus erythematosus, laboratory tests and evidence from muscle biopsy specimens of lymphocytic vasculitis are therefore unlikely to be helpful in the assessment of respiratory disease.

(Thorax 1992;47:957-960)
\end{abstract}

Department of S A Evans

W J M Kinnear

L atson

Department of Immunology N D Hopkinson R J Powell

University Hospital Nottingham NG7 2UH

Correspondence to: Dr $S$ A Evans, Unit M6, Manchester Royal Infirmary, Manchester M13 9WL (reprints will not be

available)

Accepted 13 May 1992
In systemic lupus erythematosus, respiratory symptoms occur in $44-65 \%$ of patients and pulmonary function tests give abnormal results in $67-88 \% .^{1-5}$ The commonest abnormalities are reduced carbon monoxide transfer factor and lung volumes, ${ }^{1467}$ but reductions in static mouth pressures have been reported, which raise the possibility of respiratory muscle weakness as a feature of this disease..$^{8-12}$

Lymphocyte count, anti-DNA antibody titres, immune complexes and complement abnormalities are reported to reflect disease activity in active lupus nephritis, ${ }^{13-17}$ but changes in such tests do not parallel episodes of acute cerebral lupus erythematosus. ${ }^{18}$ The extent to which pulmonary involvement can be predicted by laboratory tests is unclear. Grennan and coworkers found that C3, C4, and DNA binding capacity did not correlate with pulmonary involvement in 22 patients with systemic lupus erythematosus, the majority of whom were on treatment. ${ }^{19}$ The value of other laboratory tests in predicting lung involvement, especially in untreated patients, remains unknown.

Histological evidence of lymphocytic vasculitis in muscle biopsy specimens is a notable finding in connective tissue disorders, and demonstrates muscle vascular involvement that is often subclinical but implies systemic disease activity. ${ }^{20}$ Lymphocytic vasculitis can occur with a normal serum complement and lymphocyte count, and may be an independent predictor of disease activity. ${ }^{21}$ The degree to which histological evidence of lymphocytic vasculitis in limb muscles reflects respiratory muscle strength has not been investigated.

We have therefore prospectively studied a group of treated and untreated patients with systemic lupus erythematosus to determine if laboratory tests can predict lung disease, and whether lymphocytic vasculitis in quadriceps muscle is paralleled by a reduction in inspiratory muscle strength.

\section{Patients and methods}

PATIENTS

The study population was recruited prospectively from the connective tissue disease/ immunology outpatient clinic and consisted of two groups: group 1-consecutive newly presenting untreated patients; and group 2 -treated patients with active disease from 
Figure 1 A photomicrograph of lymphocytic vasculitis in a biopsy sample of quadriceps muscle showing lymphoid cells infiltrating and surrounding small blood vessel walls in association with endothelial cell swelling.

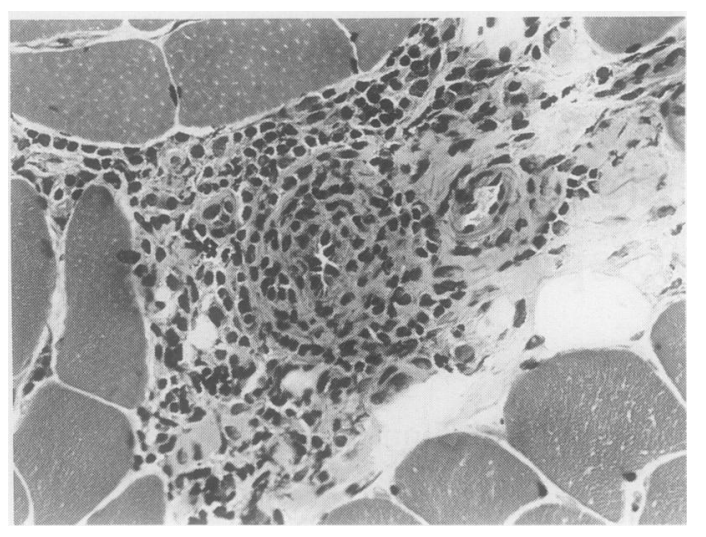

whom a muscle biopsy specimen was taken as part of their disease assessment. There was no selection on the basis of respiratory symptoms.

All patients with systemic lupus erythematosus satisfied at least four of the revised American Rheumatism Association criteria. ${ }^{22}$ Twenty seven patients were studied (26 of whom were female) with a median age of 44 years (range 20-83); eight were current smokers and five were past smokers. Ten patients had received no treatment, but 14 had been treated with prednisolone, 11 with hydroxychloroquine, and nine with azathioprine. Of the total, 16 patients were referred by their general practitioner and six by internal hospital referral, and five were tertiary referrals.

\section{METHODS}

Respiratory symptoms were recorded for all new untreated patients. Investigations for each patient were completed within one week and included lymphocyte count (Coulter counter), erythrocyte sedimentation rate (Westergren), search for antibodies to ribonucleoprotein (RNP), Smith (Sm), Ro and $\mathrm{La}^{23}$ and quantitation of plasma C3 degradation products (C3dg) by double decker rocket immunoelectrophoresis adapted from the method of Brandslund et al. . $^{24}$

Biopsy specimens from the vastus lateralis muscle were obtained by a lateral approach in

Comparison of lung function between patients with normal and abnormal results in laboratory tests and biopsy specimens

\begin{tabular}{|c|c|c|c|c|c|c|}
\hline & $F E V_{1}$ & $F V C$ & $T_{L C O}$ & $K_{c o}$ & $T L C$ & Pmo \\
\hline \multicolumn{7}{|l|}{ ESR } \\
\hline $\operatorname{Normal}(n=10)$ & $85(28)$ & $81(26)$ & $91(23)$ & $101(14)$ & $90(24)$ & $65(21)$ \\
\hline Elevated $(n=17)$ & $99(18)$ & $92(12)$ & $81(20)$ & $89(23)$ & $92(11)$ & $84(26)$ \\
\hline \multicolumn{7}{|l|}{ C3dg } \\
\hline Normal $(n=19)$ & $97(21)$ & $92(18)$ & $89(17)$ & $93(13)$ & $95(15)$ & $82(30)$ \\
\hline Elevated $(n=8)$ & $88(26)$ & $80(18)$ & $74(28)$ & $93(32)$ & $84(18)$ & $71(27)$ \\
\hline \multicolumn{7}{|l|}{ LV } \\
\hline Absent $(n=12)$ & $95(24)$ & $87(20)$ & $93(21)$ & $93(15)$ & $96(18)$ & $77(29)$ \\
\hline Present $(n=10)$ & $87(22)$ & $85(21)$ & $81(16)$ & $95(17)$ & $87(17)$ & $76(30)$ \\
\hline \multicolumn{7}{|l|}{ Lymphocyte count } \\
\hline $\operatorname{Normal}(\mathrm{n}=7)$ & $89(26)$ & $87(26)$ & $97(23)$ & $99(12)$ & $100(26)$ & $61(30)$ \\
\hline Low $^{\star}(n=20)$ & $96(21)$ & $88(16)$ & $81(19)$ & $92(23)$ & $88(11)$ & $83(27)$ \\
\hline
\end{tabular}

Lung function is given as mean (SD) \% predicted.

ESR - erythrocyte sedimentation rate (elevated is $>20 \mathrm{~mm}$ in one hour); C3dg-C3 degradation products (elevated is $>15$ units $/ \mathrm{ml}$ ); LV-lymphocytic vasculitis; FEV forced expiratory volume in one second; FVC-forced vital capacity; TLCo-carbon monoxide transfer factor; $\mathrm{Kco}$ - transfer coefficient; TLC-total lung capacity; Pmomouth pressure.

$\star$ Low lymphocyte count is $<1.5 \times 10^{9} / \mathrm{ml}$. the mid thigh under local anaesthesia with a Bergstrom percutaneous needle. Biopsy samples were obtained from 22 patients; the remaining five refused. Lymphocytic vasculitis was defined as lymphoid cells infiltrating and surrounding small blood vessel walls, in association with endothelial cell swelling (figure 1):

Forced expiratory volume in one second $\left(\mathrm{FEV}_{1}\right)$ and forced vital capacity (FVC) were measured (Vitalograph TM Ltd), as were total lung capacity (TLC) (helium dilution method) and carbon monoxide transfer factor (TLCO) and transfer coefficient (Kco) (single breath method, P K Morgan Ltd). Mouth pressure (Pmo) during a maximal sniff was measured by a catheter mounted transducer (Gaeltec Ltd: model CT/S1-2), according to the method described by Koulouris et al..$^{25}$ Measurements for Pmo were obtained in 23 patients; the catheter was temporarily unavailable when the other four patients were assessed. A normal range for Pmo has been established for our laboratory from 100 consecutive patients attending a dermatology clinic, excluding those with malignant or systemic disease (Kinnear $e t$ al, unpublished data).

Correlations were determined by the Pearson product moment correlation coefficient, significance levels being taken from standard tables. ${ }^{26}$ Unpaired student's $t$ tests were used to investigate the relationship of lung function with the presence of antibodies to Ro and $\mathrm{La}$, lymphocytic vasculitis, and abnormal results in laboratory tests.

The study was approved by the University Hospital ethical committee.

\section{Results}

Comparisons of lung function in patients with normal and abnormal laboratory test results are presented in the table. Erythrocyte sedimentation rate was raised ( $>20 \mathrm{~mm}$ in one hour) in 17 patients, and C3dg was elevated (over 15 units/ $\mathrm{ml})$ in eight patients. Lymphopenia $(<1.5 \times$ $10^{9}$ cells $/ \mathrm{ml}$ ) was seen in 20 patients. Six patients had antibodies to Ro and La, four to Ro alone, and 13 to neither, of whom five were RNP positive and two had unidentified extractable nuclear antigens.

The histological appearance of muscle biopsy specimens showed evidence of lymphocytic vasculitis in ten patients, two of whom had an elevated creatine kinase (CK). Type II fibre atrophy was coexistent with lymphocytic vasculitis, and was present in isolation in three patients.

Lung function values of $<80 \%$ predicted were taken as abnormal, except for TLCO and Pmo, where $<70 \%$ was considered abnormal. Lung function results were abnormal in 12 of the 27 patients $(44 \%)$; percentage predicted FVC was reduced in seven patients, TLCO in five, $\mathrm{FEV}_{1} / \mathrm{FVC}$ ratio (below $70 \%$ ) in two, and Pmo in ten. Of the ten untreated patients, lung function was abnormal in two, both having a reduced TLCo, and Pmo was low in four. The percentage predicted TLC was significantly lower in the treated patients than in the untreated group $(p<0.02)$. 
Figure 2 Relation between lymphocyte count and $\%$ predicted total lung capacity (TLC).

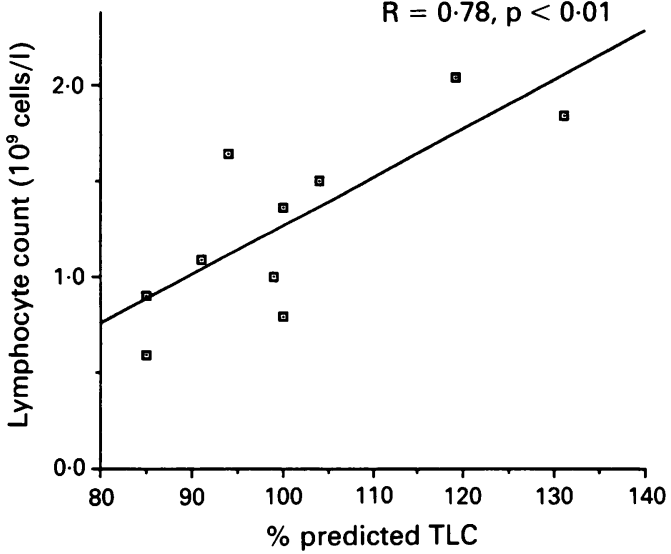

In the untreated patients, relationships between lung function and laboratory results were as follows. The percentage predicted TLC correlated with lymphocyte count ( $\mathrm{p}<0.01, \mathrm{r}=0.78$, fig 2 ), and those with lymphocytic vasculitis shown on muscle biopsy specimens had lower percentage predicted $\mathrm{FEV}_{1}$ and FVC than those without ( $\mathrm{p}<0.002$, $\mathrm{p}<0.05$ respectively). However, lung function did not correlate with laboratory results in the treated patients or in the combined group. Furthermore, histological evidence of lymphocytic vasculitis was not predictive of lower Pmo values $(p=0.95)$. Type II fibre atrophy was not predictive of any respiratory indices. Antibodies to Ro or Ro with La were not associated with abnormal lung function results or the presence of lymphocytic vasculitis.

\section{Discussion}

In systemic lupus erythematosus a number of laboratory tests may be used clinically to assess the presence and activity of nephritis. ${ }^{13-17} \mathrm{We}$ have tried to establish if it is similarly possible to predict the presence of respiratory disease. Our study shows that, in general, current laboratory tests and histological evidence of lymphocytic vasculitis in muscle biopsy specimens do not reflect abnormalities of lung function.

In this study abnormal lung function results were found in $44 \%$ of patients. This contrasts with previous studies, which have shown a higher prevalence of abnormalities of lung function of $67-88 \% .{ }^{146-819}$ Likewise, the prevalence of respiratory symptoms $(40 \%$ of newly presenting untreated patients) was also lower than in previous studies $(44-65 \%))^{1-5}$ There are several possible reasons for our lower rate of abnormalities. In some previous studies the selection criteria are not stated, and hence bias towards those with severe disease or respiratory symptoms cannot be excluded. ${ }^{19} \mathrm{~A}$ similar bias may also occur in studies undertaken at tertiary referral centres for systemic lupus erythematosus. ${ }^{148}$ In contrast to previous studies, we recruited a group of newly presenting untreated patients, so we are likely to have included a larger proportion of untreated patients $(37 \%)$. We consequently may have seen patients at an earlier stage of their disease. Finally, studies vary in their definition of an abnormal lung function value, some taking $<80 \%$ predicted as abnormal for TLco. If we adopt this criterion, our overall prevalence of abnormalities rises to $52 \%$, although this is still comparatively low. The true prevalence of abnormalities of lung function in systemic lupus erythematosus remains unclear but, in view of the unselected nature of our patients (including both treated and untreated), our estimate may be more representative.

Several investigators have found that laboratory results correlate with the presence, severity, and treatment response of active lupus nephritis. ${ }^{13-17}$ However, there have been few attempts to relate lung disease to results of laboratory tests. Grennan et al ${ }^{19}$ studied 22 patients, 17 of whom were currently on corticosteroids, and found no correlation between reduced TLCO and C3, C4, DNA binding capacity, or rheumatoid factor positivity. However, Gibson et $a l^{8}$ found an unspecified "weak correlation" between lung function abnormalities and higher levels of antinuclear factor and DNA binding in 30 patients, 26 of whom were receiving corticosteroids at the time of assessment. Our study contrasts with these studies in several ways. First, in addition to conventional laboratory markers of disease activity we quantified serum $\mathrm{C} 3 \mathrm{dg}$, which is a more sensitive indicator of complement activation than total $\mathrm{C} 3$ and $\mathrm{C} 4$ levels, which are dependent on the balance between synthesis and activation. ${ }^{27}$ Furthermore, we felt that the presence of lymphocytic vasculitis in muscle is likely to be indicative of systemic disease activity. ${ }^{20}$ Second, we have also studied a group of untreated patients and are therefore able to exclude treatment effects. It is possible that treatment could alter laboratory indices without a corresponding effect on lung function, or could itself adversely affect lung function (as in the case of steroid induced myopathy).

Our finding that laboratory tests and lung function are not correlated in patients with systemic lupus erythematosus is in broad agreement with previous work, and contrasts with renal disease in this condition. The fact that the few associations present were in the untreated group (that is, between lymphocytic vasculitis and $F E V_{1}$ and $F V C$ ) may suggest that treatment effects may obscure associations between laboratory indices and lung function. However, other reasons for the lack of correlation could be that active disease was confined to other organs, or that inappropriate measures of lung function were used. Alternatively, there may be some patients who had previous lung involvement, with permanent changes in lung function, in whom the disease is now quiescent and results of laboratory tests normal, and others for whom abnormal laboratory may presage future lung involvement.

Antibodies to Ro, or Ro with La were not associated with abnormal lung function results or with the presence of lymphocytic vasculitis, 
in contrast to their association with the development of renal disease in systemic lupus erythematosus, ${ }^{28}$ and chest symptoms in primary Sjögren's syndrome. ${ }^{29}$

The relationship between respiratory muscle strength and immunological indices has not been examined previously. Pmo during a maximal sniff was chosen as a measurement of global inspiratory muscle strength as it correlates well with oesophageal sniff pressures (Poes), and does not require the passage of an oesophageal balloon/transducer. ${ }^{25}$ Static mouth pressures (PImax) were not used as they are less reproducible and have a wider normal range than sniff pressures. ${ }^{30}$ Sniff Poes has also been shown to be useful in discriminating between those who have a low PImax caused by poor technique and those who have inspiratory weakness. ${ }^{31}$ There are conflicting views about respiratory muscle function in systemic lupus erythematosus, especially in the aetiology of shrinking lung syndrome, ${ }^{12}$ but our results show that a low Pmo during a maximal sniff is common $(37 \%)$ and that it can be markedly reduced, with four of the patients having a Pmo below $50 \%$ predicted. We have chosen $<70 \%$ predicted as "low," but acknowledge that this is rather arbitrary. Previous authors have suggested use of the mean minus two standard deviations to derive a lower limit of the normal range for sniff pressures. ${ }^{30}$ This, however, is problematical, as the distribution of Pmo during a maximal sniff in our reference population was skewed to the right. We hypothesised that lymphocytic vasculitis in biopsy specimens of quadriceps muscle might be associated with a reduction in Pmo but we were unable to find such a relationship. This could be because lymphocytic vasculitis is not associated with weakness of the involved muscle (and we have not investigated this for the quadriceps), or because muscle disease in systemic lupus erythematosus is patchy in distribution.

In summary, although we have found some associations between laboratory results and lung function in untreated patients, we conclude that these tests are unlikely to be clinically helpful in the assessment of respiratory disease in systemic lupus erythematosus. Whether such tests can predict the progression of respiratory disease in systemic lupus erythematosus remains unanswered and would require a longitudinal study. Because abnormalities are common and often asymptomatic, routine testing of respiratory function in this condition would seem indicated.

We wish to acknowledge and thank Dr D K Robson, Consultan Neuropathologist, and Dr J S Lowe, Reader and Honorary Consultant in Neuropathology, for their help and expertise in interpreting the muscle biopsy material and for the photomicrograph of lymphocytic vasculitis.

1 Silberstein SL, Barland P, Grayzel AI, Koerner SK. Pulmonary dysfunction in systemic lupus erythematosus: prevalence, classification and correlation with other organ prevalence, classification and correlation with

2 Alarcon-Segovia D, Alarcon DG. Pleuro-pulmonary manifestations of systemic lupus erythematosus. Dis Chest 1961;39:7-17.

3 Estes D, Christian CL. The natural history of systemic lupus erythematosus by prospective analysis. Medicine (Baltimore) 1971;50:85-95.

4 Grigor R, Edmonds J, Lewkonia R, Bresnihan B, Hughes
GRV. Systemic lupus erythematosus, A prospective analysis. Ann Rheum Dis 1979;37:121-8.

5 Dubois EL, Wierchowieki M, Cox MB, Wiener JM Duration and death in systemic lupus erythematosus. JAMA 1974;227:1399-402.

6 Hoffbrand BI, Beck BR. Unexplained dyspnoea and shrinking lungs in systemic lupus erythematosus. $B M J$ 1965;i:1273-7.

7 Andonopoulos AP, Constantopoulos SH, Galanopoulo V, Drosos AP, Acritidis NC, Moutsopoulos HM. Pulmonary function of nonsmoking patients with systemic lupus erythematosus. Chest 1988;94:312-15.

8 Gibson GJ, Edmonds JP, Hughes GRV. Diaphragm function and lung involvement in systemic lupus erythematosus. Am J Med 1977;63:926-32.

9 Martens J, Demedts M, Vanmeenen MT, Dequeker J Respiratory muscle dysfunction in systemic lupus erythematosus. Chest 1983;84:170-5.

10 Wilcox PG, Stein HB, Clarke SD, Pare PD, Pardy RI. Phrenic nerve function in patients with diaphragm weakness and systemic lupus erythematosus. Chest 1988;93:352-8.

11 Worth H, Grahn S, Lakomek HJ, Bremer G, Goeckenjan G Lung function disturbances versus respiratory muscle fatigue in patients with systemic lupus erythematosus. Respiration 1988;53:81-90.

12 Laroche CM, Mulvey DA, Hawkins PN, Walport MJ, Strickland B, Moxham J, et al. Diaphragm strength and shrinking lung syndrome of systemic lupus erythematosus. $Q J$ Med (New series) 1989;71:429-39.

13 Lloyd W, Schur PH. Immune complexes, complement, and anti-DNA in exacerbations of systemic lupus erythematosus (SLE). Medicine (Baltimore) 1981;60:208-17.

14 Rivero SJ, Diaz-Jouanen E, Alarcon-Segovia D. Lymphopenia in systemic lupus erythematosus. Arthritis Rheum 1978;21:295-305.

15 Pussell BA, Lockwood CM, Scott DM, Pinching AJ, Peters DK. Value of immune-complex assays in diagnosis and management. Lancet 1978;ii:359-63.

6 Hecht B, Siegel N, Adler M, Kashgarian M, Hayslett JP. Prognostic indices in lupus nephritis. Medicine (Baltimore) 1976;55:163-81.

17 Levinsky RJ, Cameron JS, Soothill JF. Serum immune complexes and disease activity in lupus nephritis. Lance 1977;i:564-7.

8 Winfield JB, Brunner CM, Koffler D. Serological studies in patients with systemic lupus erythematosus and central nervous system dysfunction. Arthritis Rheum 1978;31:289-93.

19 Grennan DM, Howie AD, Moran F, Buchanan WW Pulmonary involvement in systemic lupus erythematosus. Ann Rheum Dis 1978;37:536-9.

20 Lowe JS, Stevens A, Powell RJ. Detection of subclinical inflammatory involvement of muscle in connective tissue disorders by needle biopsy. J Pathol 1986;148:72A.

21 Hopkinson ND, Doherty $M$, Powell RJ. Laboratory parameters associated with lymphocytic vasculitis in patients with systemic lupus and mixed connective tissue disease. Electroencephalogr Clin Neurophysiol 1991;78:4.

22 Tan EM, Cohen AS, Fries JF, Masi AT, McShane DJ, Rothfield NF. The 1982 revised criteria for the classification of systemic lupus erythematosus. Arthritis Rheum 1982;25:1271-7.

23 Mackay IR. Autoimmunity in relation to lupus eryth ematosus. In Wallace DJ, Dubois EL, eds. Dubois' lupus erythematosus. 3rd edition. Philadelphia: Lea Febiger, 1987:44-52.

24 Brandslund I, Siersted HC, Svehag SE, Tiesner B. Double decker rocket immunoelectrophoresis for direct quantitation of complement C3 split products with C3d specificities in plasma. J Immunol Methods 1981;44:63-71.

25 Koulouris N, Mulvey DA, Laroche CM, Sawicka EH, Green M, Moxham J. The measurement of inspiratory muscle strength by sniff esophageal, nasopharyngeal, and mouth pressures. Am Rev Respir Dis 1989;139:641-6.

26 Fisher RA, Yates F. Statistical tables for biological, agricultural and medical research. 6th edition. Edinburgh: Oliver and Boyd, 1967:63.

27 Morrow WJW, Williams DJP, Ferec C, Casburn-Budd R, Isenberg DA, Paice E, et al. The use of $\mathrm{C} 3 \mathrm{~d}$ as a means of monitoring classical activity in systemic lupus erythematosus and rheumatoid arthritis. Ann Rheum Dis 1983;42:668-71.

28 Wasicek CA, Reichlin M. Clinical and serological differences between systemic lupus erythematosus patients with antibodies to Ro versus antibodies to Ro and La. J Clin Invest 1982;69:835-43.

29 Kelly CA, Foster H, Pal B, Gardiner P, Malcolm AJ, Charle $\mathrm{P}$, et al. Primary Sjogren's syndrome in north east England-a longitudinal study. $\mathrm{Br} J$ Rheumatol 1991;30:437-42.

30 Miller J, Moxham J, Green M. Sniff as a test of diaphragmatic function. Clin Sci 1985;69:91-6.

31 Laroche CM, Mier AK, Moxham J, Green M. The value of sniff esophageal pressures in assessment of global inspiratory muscle strength. Am Rev Respir Dis piratory muscle
$1988 ; 138: 598-603$. 